\title{
Paucity of adaptive selection in PmrAB two-component system may resist emergence of colistin resistance in Acinetobacter baumannii
}

1

2

3

4

5

Sudhakar Pagal', Rajagopalan Saranathan ${ }^{1,3}$, Anshu Rani, ${ }^{1,4}$, Archana Tomar ${ }^{2,5}$, K. P.

Arunkumar $^{2,6}$, K. Prashanth ${ }^{1 *}$

${ }^{1}$ Nosocomial Pathogen Biology Lab, Department of Biotechnology, School of Life Sciences, Pondicherry University, Puducherry, India

${ }^{2}$ Laboratory of Molecular Genetics, Centre for DNA Fingerprinting and Diagnostics (CDFD), Hyderabad, India

\section{*Corresponding author}

Dr. K. Prashanth,

Department of Biotechnology, School of Life Sciences, Pondicherry University, R. Venkataraman Nagar, Kalapet, Puducherry - 605014

prashi2k@gmail.com; Tel: (+91) 413 2654473; Fax: (+91) 4132656742

\section{Present addresses:}

${ }^{3}$ Department of Microbiology and Immunology, Albert Einstein College of Medicine, Bronx, New York -10461

${ }^{4}$ Kusuma School of Biological Sciences, Indian Institute of Technology (IIT), New Delhi, India

${ }^{5}$ Institute of Experimental Genetics, Helmholtz Zentrum München, GmbH, Neuherberg, Germany

${ }^{6}$ State Key Laboratory of Silk Worm Genome Biology, South-West University, Chongqing, China

Running title: Paucity of adaptive selection to sustain colistin resistance in Acinetobacter baumannii

Keywords: Colistin resistance; PmrAB; Point mutation; Selection analysis; Purifying selection; Acinetobacter baumannii 


\section{Abstract}

Investigations on the selection pressure acting on point mutations in PmrAB two-component system may provide insights into the future of colistin therapy in Acinetobacter baumannii, since mutations in $p m r A B$ are implicated in colistin resistance. We performed adaptive selection analysis of $p m r A B$ and compared with the available data on colistin resistant strains. We analysed PmrAB sequences in 3113 draft genomes of A. baumannii obtained from RefSeq database. Adaptive selection analysis was performed by two widely used programs namely, HyPhy and PAML. In addition, to examine the reliability of the approach, the same analysis was performed on gyrA of Escherichia coli and Salmonella enterica, since adaptive mutations on gyrA confer quinolone resistance. Mutations that had caused colistin resistance were found to be neither adaptive nor polymorphic, rather they occur at sites that are either under neutral or purifying selection. Strong negative evolutionary selection pressure is also observed at sites throughout both PmrA and PmrB. Sites with high levels of polymorphisms in PmrAB were found to be under neutral selection. Notably, there was no sign of positive selection. Some of them are rather deleterious. These conditions might be maintaining the incidence of colistin resistance in A. baumannii under check. Therefore, in the context of colistin resistance, natural selection plays only a minor role and we assert that in future, $A$. baumannii may not be able to sustain and successfully disseminate colistin resistance. Therefore, at present the concerns raised about continuing the usage of colistin for the treatment against $A$. baumannii infections appears to be unnecessary.

\section{Introduction}

Single nucleotide polymorphisms (SNPs) contribute greatly towards the microevolution of a bacterium (Chouard, 2010; Reznick \& Ricklefs, 2009). Consequently, these bacteria are able 
to adapt to their environment comparatively faster without any significant associated costs.

These mutations also have a profound effect on drug resistance and pathogenesis. In recent years, colistin resistance has been found to be due to SNPs in the genes encoding the twocomponent system (TCS) PmrAB, as well as in the lpx operon, that are responsible for the production and regulation of lipopolysaccharide (LPS) in bacterial cell walls (Moffatt et al., 2010; Snitkin et al., 2013; Thi Khanh Nhu et al., 2016).

PmrAB is thought to regulate lipid-A biosynthesis of gram negative outer membranes (Boll et al., 2016). Lipid-A is a constituent of the outer membrane LPS, which is the target of colistin. Colistin resistant strains of $A$. baumannii have modifications and/or loss of LPS from their outer membrane, with concomitant mutations in the $p m r C A B$ and/or $l p x$ operon (Boll et al., 2016; Carretero-Ledesma et al., 2018). Emergence of such resistance is worrisome, since colistin is the last-choice drug against multidrug resistant $A$. baumannii. The objective of this study was therefore to identify the hyper-variable regions of the TCS PmrAB in A. baumannii to gain insights into their contribution towards the structure and function of this TCS. Since point mutations in PmrAB have been implicated in resistance to colistin, sequence analysis of PmrAB in the context of the evolutionary selection pressure acting on these mutations may provide insights into the fate of colistin resistance in A. baumannii. We report that, both PmrA and PmrB are under strong purifying evolutionary selection pressure. In addition, there was no sign of adaptive evolution. Mutations that cause colistin resistance are neither adaptive nor polymorphic. Some of them are rather deleterious. Therefore, it is highly unlikely that these mutations will sustain in the long term and hence, A. baumannii may not be able to emerge as a colistin-resistant organism.

\section{Methods}


Minimum inhibitory concentration (MIC) for colistin were performed according to European Committee on Antimicrobial Susceptibility Testing guidelines (EUCAST, 2017). pmrA coding sequences were amplified by in house designed primers and custom sequenced (Supplementary methods). For selection analysis, 3113 genomes were retrieved from RefSeq from which, $p m r A$ and $p m r B$ sequences were extracted. $p m r A B$ sequences originated from colistin resistant strains that appeared in the literature were also included. Selection analysis was performed with Single Likelihood Ancestor Counting method of the HyPhy package, and CodeML of the PAML package. All methods in detail have been provided in

\section{Supplementary methods.}

\section{Results}

\section{Mutation hotspots in PmrAB are not responsible for colistin resistance}

In our observations, two of our clinical isolates, PKAB15 and PKAB19 were identified to be colistin resistant (Table 1). We amplified and performed sequencing of the $p m r A$ genes from these two isolates. One non-synonymous mutation in each of these isolates was identified in pmrA, when compared to the reference strain A. baumannii ATCC17978, both of which (D10N in PKAB15, and R212L in PKAB19) have never been reported hitherto. Both these mutations change charged amino acids with uncharged ones which, we believe might have significant alterations on the structure of the protein to bring about colistin resistance.

Across all the 3113 genomes investigated in the study, 43 sites with non-synonymous mutations were identified in pmrA (Table 2). Of these, five were highly polymorphic sites. Most of the mutations occur in the signal receiver domain and the region connecting the receiver domain to the DNA-binding domain (Figure 1). The DNA binding domain recorded as few as seven sites with non-synonymous mutations, four of which had rare mutations while one was among the five most polymorphic sites. A well-conserved DNA binding 
domain emphasizes the importance of genes that are regulated by PmrAB, and therefore, it cannot afford many mutations in this region.

One hundred fifty sites with amino acid substitutions in the PmrB protein sequence were found in our study, of which, 64 sites had rare mutations, each occurring in $\leq 0.1 \%$ of the genomes analysed (Table 3). Eighteen of the sites were highly polymorphic (Table 3 \& Figure 2, middle panel). Most of these belong to the two trans-membrane regions and the intracellular domain connecting them. The HATPase_c domain, which binds the ATP moiety required for auto-phosphorylation of the sensor kinase, is the most conserved domain. In particular, with the exception of a few rare mutations, the ATP binding domain, $\mathrm{Mg}^{2+}$ binding domain and the G-X-G motif were well conserved (Figure 2, upper \& middle panel). The $\mathrm{Mg}^{2+}$ metal cofactor and the G-X-G motif line the ATP binding pocket and are therefore crucial for the function of PmrB. Clearly, mutations in these sites can severely compromise its function.

Most of the amino acid substitutions previously reported in PmrAB in isolates of $A$. baumannii that are resistant to colistin were found to be at non-polymorphic sites in our analysis. To date, four sites in $p m r A$ and 26 sites in $p m r B$ have been described as having nonsynonymous mutations in the isolates resistant to colistin (Supplementary Table S1). Only one of the four resulting amino acid substitutions in PmrA and only three of the 26 in PmrB belong to polymorphic sites. In PmrA, the only substitution (S119T) at a polymorphic site, which has been shown to correlate with colistin resistance, occurs in the region that connects the domain of the signal receptor to the DNA binding domain (Figure 1, top \& middle panel). In the case of PmrB, two of the three polymorphic sites in PmrB of colistin-resistant isolates have frequent substitutions $\mathrm{A} 142 \mathrm{~V}$ and P170Q; both sites fall into the intracellular domain of the protein. P360Q mutation occurs in the third polymorphic site, which lies in the 
ATPase domain of PmrB (Figure 2, top \& middle panel, Supplementary table S1). Since the amino acid substitutions previously described in colistin resistant isolates of $A$. baumannii are sporadic observations, we understand that both PmrA and PmrB are constrained when accommodating non-synonymous SNPs. Therefore colistin resistance has not been an emerging phenomenon in the case of $A$. baumannii, unlike resistance to other antibiotics. We therefore examined the selection pressure at each amino acid site of the TCS, to see if there is negative selection acting on them, which could be the cause of the underlying mutation constraints.

\section{Both PmrA and PmrB are subject to negative selection pressure}

To estimate the strength of natural selection pressure acting on each amino acid site in PmrA and PmrB, we performed codon based selection analysis. We observed significant negative selection (also known as 'purifying selection') all through both the protein sequences. In PmrA, 43 sites out of 224 are subjected to a strong negative selection pressure. As a result, these sites and the regions around them remain conserved (Figure 1, bottom panel). Functionally important sites, both in the signal receiver domain and in the DNA binding domain, exhibit a much more negative selection pressure than the rest of the sequence. While no signs of positive selection were found in PmrA, sites with high levels of polymorphism were found to be under neutral selection instead. Three of the four mutated sites of PmrA (M12K/M12I, P102H, S119T and L206P) that are reported in colistin-resistant isolates of $A$. baumannii belong to these highly polymorphic regions, which are under neutral selection

(Supplementary Table S1 \& Figure 1, middle panel). protein sequence. As in the case of PmrA, these sites and regions around them are fairly 
conserved in PmrB. In particular, the extracellular region, which spans the functional sites of the HATPase_c, HisKA and HAMP domains, has far fewer mutations than the rest of the molecule, due to the presence of the majority of the sites under negative selection therein (Figure 2, top \& middle panel). Notably, though most of these sites are under purifying selection, the functional domains managed to acquire amino acid substitutions (Figure 2, middle \& bottom panel). This can explain the loss of fitness associated with colistin resistance in previous reports. As many as 23 out of the 26 amino acid substitutions in PmrB that occur in colistin-resistant isolates fall in functional domains (Supplementary Table S1

\& Figure 2, top panel). However, these mutations occur mainly on sites that are under neutral selection (Figure 3A), each of them being delimited by the sites under negative selection in the functional domains (Figure 2, top \& bottom panels). However, there exists a site at 153 of PmrB that is under significant positive selection (Table $\mathbf{3}$ \& Figure 3B).

The SLAC method is equivalent to the site model of the equally well accepted program CodeML of the PAML package, but both employ different sets of procedures and algorithms (Yang, 2007). To examine the consistency of the obtained results, we performed the same selection analysis for PmrA and PmrB with CodeML. CodeML produced similar results to that we obtained with SLAC of HyPhy; it did not find any sign of significant positive selection in any of the sites of PmrA and PmrB (Supplementary file S2). This increases the reliability of the study and reinforces our results on the lack of adaptive selection on PmrAB.

Taken together, mutations in PmrAB TCS that are held responsible for colistin resistance in A. baumannii are neither adaptive nor polymorphic (Figure 3A). Rarher, the PmrAB TCS is under strong purifying selection to sustain colistin resistance in the long term. Therefore, it is plausible to believe that resistance to colistin, when occurred due to mutations in $\operatorname{PmrAB}$, is not disseminated owing to the underlying purifying selection that causes the loss of fitness. 
Selection analysis of gyrA of $E$. coli and $S$. enterica was able to detect signatures of

\section{adaptive evolution that validates our approach}

174

To validate this approach of selection analysis and increase reliability of the results, we employed the same methodology to detect positively selected sites in well-known antibiotic targets that cause antibiotic resistance. We considered DNA gyrase A (gyrA) to be the most appropriate for this purpose, as there is abundant of literature that share common findings about mutations in this gene in multiple organisms that lead to quinolone resistance. Mutations at Ser-83 and Asp-87 in GyrA are the most frequently reported sites to be responsible for quinolone resistance in Enteric bacteria (Domínguez et al., 2002; Everett et al., 1996; Lindgren et al., 2003; Vila et al., 2001, 1994). Therefore, our results of selection analysis can be qualified as valid if these two sites are detected under the same selection analysis framework applied to $p m r A B$. Interestingly, selection analysis of gyrA successfully detected these two sites (Ser-83 and Asp-87) to be under adaptive evolution in both E. coli as well as S. enterica (Figure 3B \& Supplementary file S2). This not only substantiated the reliability of the methodology, but also validated our results obtained for $p m r A B$. In addition, this also provided evidences that adaptive evolution had an important role to play behind the emergence of quinolone resistance in E. coli and S. enterica, while it has little role to play in colistin resistance in A. baumannii.

\section{Discussion}

The emergence and spread of multidrug-resistant ESKAPE group of pathogens including $A$. baumannii have prompted many health professionals to assume that we are on the verge of a post-antibiotic era. Colistin and to some extent, tigecycline appear to be the only treatment options for treating infections caused by multidrug-resistant $A$. baumannii. In addition, the notable efficacy of colistin against tigecycline-resistant $A$. baumannii advocates colistin as 
the last option against the organism. However, reports of colistin resistance in A. baumannii have raised unprecedented concerns, as it is thought that resistance to colistin may become widespread in the future if not used judiciously. Contrary to this belief, we have shown in this work that resistance to colistin may not become a general phenomenon and these concerns are therefore unwarranted. Similar opinions were also put forwarded by Lo'pez-Rojas et al. based on the observed reduced fitness and reduced virulence of experimentally induced colistin-resistant A. baumannii isolates (Lo'pez-Rojas et al., 2011). However, they also cautioned that, though the synonymous mutations are initially not adaptive, compensatory mutations may attenuate the reduced fitness. In contrast, using selection analysis, our investigation provided more direct evidence that mutations that cause colistin resistance are neither adaptive nor polymorphic and therefore, may not take over the global population.

In A. baumannii, resistance to colistin occurs in two mechanisms: enzymatic modification of lipid A moieties of the bacterial cell wall, either by the addition of phosphoethanolamine or galactosamine, or hyperacylation, and complete loss of cell wall lipo-polysaccharide (LPS) due to inactivation of lipid A biosynthesis (Beceiro et al., 2011; Boll et al., 2015; Henry et al., 2011; Moffatt et al., 2011, 2010; Pelletier et al., 2013). Colistin resistance by both mechanisms is the result of deletions and/or substitutions in the PmrAB two-component system (Adams et al., 2009; Arroyo et al., 2011; Beceiro et al., 2011). Resistance to colistin due to mutations in PmrAB is the most common mode of colistin resistance.

PmrAB mutation analysis, in conjunction with domain analysis suggests that the signal receptor domain and the DNA binding domain, as well as the functional sites therein are ideally conserved in PmrA. This indicates that PmrA transduces a very specific signal, input from PmrB and in turn, regulates a limited and non-degenerate set of genes. On the other hand, the transmembrane domains as well as the intracellular domain of PmrB are highly 
variable. Other domains such as the kinase and ATP-binding domain are comparatively conserved and contain more sites with purifying selection. Since there is only one intracellular domain delimited by transmembrane $\alpha$-helices, this domain must be recruiting the response regulator(s). Since this domain is variable, we can state that it recruits more than one response regulators and/or transcription factors, resulting in cross-talks between parallel signal transduction pathways, one of which is the cognate PmrA-mediated signalling. More detailed investigations at the molecular level are needed to corroborate this hypothesis.

In this study, we collected 3113 draft genomes from the RefSeq database to evaluate the degree of natural selection acting on each site of PmrAB two-component system. Initially, the study considered $\mathrm{pmr} A B$ sequences only related to colistin resistant strains. This comprise of $44 p m r A$ and $39 p m r B$ sequences that were collected from the whole genomes of colistin resistant strains as well as from the full length coding sequences associated with colistin resistance that appear in the literature. Selection analysis with this dataset showed just one site with purifying selection and no adaptive selection in PmrA. Similarly, it showed neither positive nor negative selection in PmrB (Supplementary file S2). However, when all the pmr $A B$ sequences from the 3113 genomes were considered, it was found that the PmrAB TCS is under strong purifying selection. This dramatic change in the results can be attributed to the homogeneity of the initial sequence data that contains sequences associated with only colistin resistant strains. In cases where the sequences belong to a homogenous population exposed to similar environmental conditions, most of the mutations are transient mutations, which underestimates any real purifying as well as adaptive selection (Kryazhimskiy \& Plotkin, 2008). A similar scenario exists when the strains undergo convergent and parallel evolution resulting from colistin exposure (Crandall et al., 1999). The larger dataset allowed the inclusion of genomes reported worldwide over a wide range of time scale that ensures a heterogeneous set of samples/populations for analysis. 
To evaluate long term emergence of colistin resistance, we need to examine the scenario post-exposure to colistin. In addition, if any site is under adaptive selection, selection analysis should identify signatures of adaptive selection from a sufficiently large dataset, even in the absence of colistin exposure. We could then qualify these mutations are stable enough to sustain long term resistance to colistin. Most of the amino acid substitutions in PmrAB reported to date are either from longitudinal isolates of patients or induced in laboratory conditions. Reports of clinical isolates bearing colistin resistance are scant. In addition, the colistin exposure to A. baumannii lasts as long as the treatment of the patient, and the resistance (if arises) reverts back to susceptible phenotype on withdrawal of colistin. (Adams et al., 2009; Cheah et al., 2016; Snitkin et al., 2013). Therefore, it is plausible to believe that mutations that cause colistin resistance are transient mutations owing to the short exposure to the antibiotic as clinicians prefer to give short term colistin therapy due to its association with nephrotoxicity. Further, with no evidence of compensatory mutations linked to colistin resistance identified till date, which strengthens our supposition that colistin resistant mutations may never get fixed in the global population of $A$. baumannii (Lesho et al., 2013; Lo'pez-Rojas et al., 2011; Rolain et al., 2011). This observation may not apply to the populations in micro-environments, such as a laboratory cultures.

Apparently, resistance to colistin is achieved by a cost of fitness. Studies in the past have shown reduced fitness in colistin resistant isolates, both in terms of growth rate under laboratory conditions and reduced virulence (Beceiro et al., 2014; Lo'pez-Rojas et al., 2011; López-Rojas et al., 2013). In addition, to compensate for the loss/modification of the LPS, the transcriptome and the corresponding proteome are largely shifted towards expression of genes responsible for membrane integrity and biogenesis (Boll et al., 2016; Cheah et al., 2016; Henry et al., 2011). A recent work confirms that surface lipoproteins are overexpressed 
integrity. These studies highlight the excessive cost of colistin resistance, and therefore, mutations in PmrAB may be deleterious and subject to strong purifying selection.

A significant number of sites in both PmrA and PmrB are under purifying selection. In addition, we also identified mutation hotspots, sites that are exceptionally polymorphic. Interestingly, sites with mutations that cause colistin resistance are not polymorphic sites. Rather, colistin resistance mutations are largely under neutral selection. In addition, a few of colistin resistance mutations are also under purifying selection (Figure 3A \& B). We suggest that these conditions maintain the incidence of colistin resistance under check. Further, loss of fitness due to colistin resistance resulting from the combined effects of neutral colistin resistance mutations and the purifying selection acting on the overall protein sequences ensure that the colistin resistance remains uncommon. The reasons for this loss of fitness include physiological costs in terms of slow growth rate, loss of membrane integrity and its compensation, and reduced virulence. In addition to this, because of the high selection pressure exerted by the host's immune system and the presence of drugs, the short exposure of the bacterium to colistin in the host, it is highly unlikely that random genetic drift can fix these mutations. These observations explain us why reports of colistin-resistant isolates of $A$. baumannii have been sporadic and they might remain so. In the near future, A. baumannii may not be able to emerge as a colistin-resistant organism, unless other mechanisms such as plasmid-mediated (e.g., mcr-1) resistance emerge.

The other mechanism of development of Colistin resistance is due to mutations in lpxACD of A. baumannii. However, unlike mutations in $\operatorname{pmr} A B$, where virtually all mutations that cause Colistin resistance are due to substitutions, mutations reported in $\operatorname{lp} x A C D$ are due to large indels, non-sense mutations and insertion sequence-mediated gene disruptions that cause complete loss of cell wall lipopolysaccharide (Carretero-Ledesma et al., 2018; Girardello et 
al., 2017; Moffatt et al., 2010). There is no direct method to analyse signatures of selection pressure from such mutations. However, it has already been reported through growth curve and virulence assays that fitness costs associated with $l p x$ mutations are even higher than those associated with pmr mutations (Beceiro et al., 2014) and therefore, lpxACD mutants are unsustainable in the long run.

One site at 153 of PmrB appears to be under adaptive selection. This site has $d N-d S$ value of $9.48851(p=0.013)$. Surprisingly, this site has never been reported to be mutated in colistin resistant strains of $A$. baumannii. This site belongs to one of the transmembrane domains of PmrB. The fact that it has so far never caused colistin resistance indicates that the positive selection gain may not overcome the cost of colistin resistance. Since the site belongs to a transmembrane domain, it is also possible that the mutations that occur at this site might serve an advantage in terms of structural stability, rather than having a functional advantage. Further, studies employing site directed mutagenesis experiments could throw additional information about this site.

The study attempted to assert the reliability of the methodology by applying it to gyrA on the basis of whether it can identify sites that are expected to be under adaptive selection in multiple organisms. The computational method of selection analysis has precisely detected the sites under adaptive evolution in GyrA, an observation which is supported by a wealth of previous literature about quinolone resistance in bacteria. In case of $E$. coli, resistance to quinolones requires multiple mutations in different genes including gyrA to achieve a clinically relevant level. The requirement for multiple mutations suggests that there is strong selection for resistance mutations invariably associated with unusually high mutation rates occurring due to antibiotic exposure. Quinolones are known to interact with the DNA-GyrA complex, rather than with the enzyme alone. One study correlated that gyrA mutations lead to 
reduction of drug binding to the protein-DNA complex to 60-fold less than that of wild-type pronounced to be associated with quinolone resistance by adaptive selection analysis

321 provides sufficient grounds to emphasize the power of the methodology to detect adaptive

322 evolution in protein coding sequences.

\section{Conclusion}

324 The anticipation and management of natural selection is an important aspect of the fight against multidrug resistance (Lesho et al., 2013). This was the central theme of this work in the context of the degree of natural selection acting on PmrAB TCS, which has been implicated in resistance to colistin. We showed that in case of resistance to colistin, natural selection plays only a minor role, if at all, and therefore, continuing use of colistin could still be a safe option. Therefore, the concerns raised by healthcare professionals regarding rapid emergence of colistin resistance and about continuing the usage of colistin for the treatment against $A$. baumannii infections are unwarranted.

\section{Acknowledgements}

333 We duly thank and acknowledge the remote access to supercomputing provided by computationally intensive analyses.

\section{Funding}

337 This work was supported by University Grants Commission, Government of India [Grant Ref. No. F. 30-70/2016 (SA-II)].

\section{Transparency declarations}

340 None to declare. 
Author contributions: SP: Literature search, Figures, Data collection, Data analysis, Bench

Critical revision of the article, administrative, technical, or logistic support; KPA:

Conception and design, analysis and interpretation, writing of the article, provision of

materials, patients, and resources; PK: Supervision of the entire work, Conceptual design of

the experiment, analysis and interpretation, writing of the article, provision of materials,

patients, resources and funding.

\section{References}

Adams, M.D., Nickel, G.C., Bajaksouzian, S., Lavender, H., Murthy, A.R., Jacobs, M.R., Bonomo, R.A., 2009. Resistance to colistin in Acinetobacter baumannii associated with mutations in the PmrAB two-component system. Antimicrob. Agents Chemother. 53, 3628-3634.

Arroyo, L.A., Herrera, C.M., Fernandez, L., Hankins, J. V., Trent, M.S., Hancock, R.E.W., 2011. The pmrCAB operon mediates polymyxin resistance in Acinetobacter baumannii ATCC 17978 and clinical isolates through phosphoethanolamine modification of. Antimicrob. Agents Chemother. $55,00256-11$.

Beceiro, A., Llobet, E., Aranda, J., Bengoechea, J.A., Doumith, M., Hornsey, M., Dhanji, H., Chart, H., Bou, G., Livermore, D.M., Woodford, N., 2011. Phosphoethanolamine modification of lipid A in colistin-resistant variants of Acinetobacter baumannii mediated by the pmrAB twocomponent regulatory system. Antimicrob. Agents Chemother. 55, 3370-3379.

Beceiro, A., Moreno, A., Fernández, N., Vallejo, J.A., Aranda, J., Adler, B., Harper, M., 2014. Biological Cost of Different Mechanisms of Colistin Resistance and Their Impact on Virulence in Acinetobacter baumannii. Antimicrob. Agents Chemother. 58, 518-526.

Boll, J.M., Crofts, A.A., Peters, K., Cattoir, V., Vollmer, W., Davies, B.W., 2016. A penicillinbinding protein inhibits selection of colistin-resistant, lipooligosaccharide-deficient Acinetobacter baumannii. Proc. Natl. Acad. Sci. U. S. A. 113, E6228-E6237.

Boll, J.M., Tucker, A.T., Klein, D.R., Beltran, A.M., Brodbelt, J.S., Davies, B.W., Trent, M.S., 2015. Reinforcing Lipid A Acylation on the Cell Surface of Acinetobacter baumannii Promotes Cationic Antimicrobial Peptide Resistance and Desiccation Survival 6, 1-11.

Carretero-Ledesma, M., García-Quintanilla, M., Martín-Peña, R., Pulido, M.R., Pachón, J., McConnell, M.J., 2018. Phenotypic changes associated with Colistin resistance due to Lipopolysaccharide loss in Acinetobacter baumannii. Virulence 9, 930-942.

Cheah, S.-E., Johnson, M.D., Zhu, Y., Tsuji, B.T., Forrest, A., Bulitta, J.B., Boyce, J.D., Nation, R.L., Li, J., 2016. Polymyxin Resistance in Acinetobacter baumannii: Genetic Mutations and Transcriptomic Changes in Response to Clinically Relevant Dosage Regimens. Sci. Rep. 6, 26233.

Chouard, T., 2010. Evolution: Revenge of the hopeful monster. Nat. News 463, 864-867.

Crandall, K.A., Kelsey, C.R., Imamichi, H., Lane, H.C., Salzman, N.P., 1999. Parallel evolution of drug resistance in HIV: Failure of nonsynonymous/synonymous substitution rate ratio to detect selection. Mol. Biol. Evol. 16, 372-382.

Domínguez, E., Zarazaga, M., Sáenz, Y., Briñas, L., Torres, C., 2002. Mechanisms of antibiotic 
resistance in Escherichia coli isolates obtained from healthy children in Spain. Microb. Drug Resist. $8,321-327$.

EUCAST, 2017. Breakpoint tables for interpretation of MICs and zone diameters, version 8.0, 2018. http://www.eucast.org/clinical_breakpoints/.

Everett, M.J., Jin, Y.F., Ricci, V., Piddock, L.J., 1996. Contributions of individual mechanisms to fluoroquinolone resistance in 36 Escherichia coli strains isolated from humans and animals. Antimicrob. Agents Chemother. 40, 2380-2386.

Finn, R.D., Clements, J., Eddy, S.R., 2011. HMMER web server: interactive sequence similarity searching. Nucleic Acids Res. 39, W29-W37.

Girardello, R., Visconde, M., Cayô, R., de Figueiredo, R.C.B.Q., da Silva Mori, M.A., Lincopan, N., Gales, A.C., 2017. Diversity of polymyxin resistance mechanisms among Acinetobacter baumannii clinical isolates. Diagn. Microbiol. Infect. Dis. 87, 37-44.

Goldman, N., Yang, Z., 1994. A codon-based model of nucleotide substitution for protein- coding DNA sequences. Mol. Biol. Evol. 11, 725-736.

Henry, R., Vithanage, N., Harrison, P., Seemann, T., Coutts, S., Moffatt, J.H., Nation, R.L., Li, J., Harper, M., Adler, B., Boyce, J.D., 2011. Colistin-Resistant, Lipopolysaccharide-Deficient Acinetobacter baumannii Responds to Lipopolysaccharide Loss through Increased Expression of Genes Involved in the Synthesis and Transport of Lipoproteins, Phospholipids, and Poly- $\beta-1,6-\mathrm{N}-$ Acetylglucosamine. Antimicrob. Agents Chemother. 56, 59-69.

Kelly, L.A., Mezulis, S., Yates, C., Wass, M., Sternberg, M., 2015. The Phyre2 web portal for protein modelling, prediction, and analysis. Nat. Protoc. 10, 845-858.

Kimura, M., 1977. Preponderance of synonymous changes as evidence for the neutral theory of molecular evolution [33]. Nature.

Kosakovsky Pond, S.L., Frost, S.D.W., 2005. Datamonkey: Rapid detection of selective pressure on individual sites of codon alignments. Bioinformatics 21, 2531-2533.

Kryazhimskiy, S., Plotkin, J.B., 2008. The population genetics of dN/dS. PLoS Genet. 4, e1000304.

Lesho, E., Yoon, E., Mcgann, P., Snesrud, E., Kwak, Y., Milillo, M., Onmus-leone, F., Preston, L., Clair, K.S., Nikolich, M., Viscount, H., Wortmann, G., Zapor, M., Grillot-courvalin, C., Courvalin, P., Clifford, R., Waterman, P.E., 2013. Emergence of Colistin-Resistance in Extremely Drug-Resistant Acinetobacter baumannii Containing a Novel pmrCAB Operon During Colistin Therapy of Wound Infections 208, 1142-1151.

Lindgren, P.K., Karlsson, Å., Hughes, D., 2003. Mutation rate and evolution of fluoroquinolone resistance in Escherichia coli isolates from patients with urinary tract infections. Antimicrob. Agents Chemother. 47, 3222-3232.

Lo'pez-Rojas, R., Dominguez-Herrera, J., McConnell, M.J., Docobo-Pere'z, F., Smani, Y., Ferna'ndez-Reyes, M., Rivas, L., Pacho'n, J., 2011. Impaired Virulence and In Vivo Fitness of Colistin-Resistant Acinetobacter baumannii. J. Infect. Dis. 203, 545-548.

López-Rojas, R., McConnell, M.J., Jiménez-Mejías, M.E., Domínguez-Herrera, J., FernándezCuenca, F., Pachón, J., 2013. Colistin Resistance in a Clinical Acinetobacter baumannii Strain Appearing after Colistin Treatment: Effect on Virulence and Bacterial Fitness. Antimicrob. Agents Chemother. 57, 4587-4589.

Marchler-Bauer, A., Lu, S., Anderson, J.B., Chitsaz, F., Derbyshire, M.K., DeWeese-Scott, C., Fong, J.H., Geer, L.Y., Geer, R.C., Gonzales, N.R., Gwadz, M., Hurwitz, D.I., Jackson, J.D., Ke, Z., Lanczycki, C.J., Lu, F., Marchler, G.H., Mullokandov, M., Omelchenko, M. V., Robertson, C.L., Song, J.S., Thanki, N., Yamashita, R.A., Zhang, D., Zhang, N., Zheng, C., Bryant, S.H., 2011. CDD: A Conserved Domain Database for the functional annotation of proteins. Nucleic Acids Res. 39. 
Moffatt, J.H., Harper, M., Adler, B., Nation, R.L., Li, J., Boyce, J.D., 2011. Insertion sequence ISAbal1 is involved in colistin resistance and loss of lipopolysaccharide in Acinetobacter baumannii. Antimicrob. Agents Chemother. 55, 3022-3024.

Moffatt, J.H., Harper, M., Harrison, P., Hale, J.D.F., Vinogradov, E., Seemann, T., Henry, R., Crane, B., St. Michael, F., Cox, A.D., Adler, B., Nation, R.L., Li, J., Boyce, J.D., 2010. Colistin resistance in Acinetobacter baumannii is mediated by complete loss of lipopolysaccharide production. Antimicrob. Agents Chemother. 54, 4971-4977.

Pelletier, M.R., Casella, L.G., Jones, J.W., Adams, M.D., Zurawski, D. V, Hazlett, K.R.O., Doi, Y., Ernst, R.K., 2013. Unique Structural Modifications Are Present in the Lipopolysaccharide from Colistin-Resistant Strains of Acinetobacter baumannii. Antimicrob. Agents Chemother. 57, 48314840 .

Reznick, D.N., Ricklefs, R.E., 2009. Darwin's bridge between microevolution and macroevolution. Nature 457, 837-842.

Rolain, J.-M., Roch, A., Castanier, M., Papazian, L., Raoult, D., 2011. Acinetobacter baumannii Resistant to Colistin With Impaired Virulence: A Case Report From France. J. Infect. Dis. 204, 11461147.

444 Snitkin, E.S., Zelazny, A.M., Gupta, J., Comparative, N., Program, S., Palmore, T.N., Murray, P.R., Segre, J.A., 2013. Genomic insights into the fate of colistin resistance and Acinetobacter baumannii during patient treatment. Genome Res. 1155-1162.

447 Sonnhammer, E.L., von Heijne, G., Krogh, A., 1998. A hidden Markov model for predicting transmembrane helices in protein sequences. Proc. Int. Conf. Intell. Syst. Mol. Biol. 6, 175-182.

Thi Khanh Nhu, N., Riordan, D.W., Do Hoang Nhu, T., Thanh, D.P., Thwaites, G., Huong Lan, N.P., Wren, B.W., Baker, S., Stabler, R.A., 2016. The induction and identification of novel Colistin resistance mutations in Acinetobacter baumannii and their implications. Sci. Rep. 6, 28291.

Vila, J., Ruiz, J., Marco, F., Barcelo, A., Goni, P., Giralt, E., De Anta, T.J., 1994. Association between double mutation in gyrA gene of ciprofloxacin-resistant clinical isolates of Escherichia coli and MICs. Antimicrob. Agents Chemother. 38, 2477-2479.

Vila, J., Vargas, M., Ruiz, J., Espasa, M., Pujol, M., CorachÁn, M., De Anta, M.T.J., Gascón, J., 2001. Susceptibility patterns of enteroaggregative Escherichia coli associated with traveller's diarrhoea: emergence of quinolone resistance. J. Med. Microbiol. 50, 996-1000.

Willmott, C.J., Maxwell, A., 1993. A single point mutation in the DNA gyrase A protein greatly reduces binding of fluoroquinolones to the gyrase-DNA complex. Antimicrob. Agents Chemother. 37, $126-127$.

461 Yang, Z., 2007. PAML 4: phylogenetic analysis by maximum likelihood. Mol. Biol. Evol. 24, 1586462 1591. 
Figure 1. Mutation analysis of PmrA of $A$. baumannii.

Top panel - The domain analysis (predicted by HMMER)(Finn et al., 2011). The secondary structure was predicted by Phyre2 web server (Kelly et al., 2015). The black triangles show functional sites of the protein (predicted by the Conserved Domain Database) (Marchler-Bauer et al., 2011). A-Active site, P-Phosphorylation site, D-Dimerization interface, R-Intermolecular recognition site. Barrels and arrows represent $\alpha$-helices and $\beta$-sheets, respectively. Numbers in brackets denote the start-end positions of the corresponding domains.

Middle panel - Positions and numbers of non-synonymous mutations across all the genomes under the analysis.

Bottom panel - Selection along the protein sequence expressed in terms of normalized $d N-d S$ (calculated by Datamonkey web server) (Kosakovsky Pond \& Frost, 2005). Asterisks indicate sites under negative selection with $\mathrm{p} \leq 0 \cdot 05$. Triangles show the sites identified in colistin resistant isolates in previous literatures.

This figure appears in colour in the online version of $J A C$ and in black and white in the print version of $J A C$.

Figure 2. Mutation analysis of PmrB of $A$. baumannii.

Top panel - The domain analysis (predicted by HMMER)(Finn et al., 2011). The secondary structure was predicted by Phyre 2 server and trans-membrane (yellow barrels) by TMHMM (Kelly et al., 2015; Sonnhammer et al., 1998). The black triangles show functional sites of the protein (predicted by the

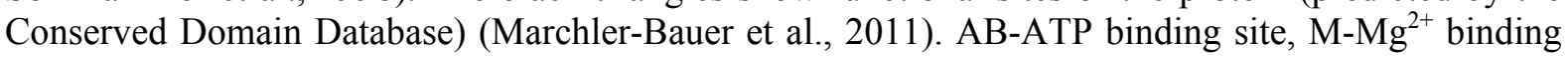
site, G-GXG motif. Barrels and arrows represent $\alpha$-helices and $\beta$-sheets, respectively. Yellow coloured regions of the $\alpha$-helices denote transmembrane domains. Numbers in brackets denote the start-end positions of the corresponding domains.

Middle panel - Positions and numbers of non-synonymous mutations across all the genomes under the analysis.

Bottom panel - Selection along the protein sequence in terms of normalized $d N-d S$ (calculated by Datamonkey web server) (Kosakovsky Pond \& Frost, 2005). Asterisks indicate sites under negative selection with $\mathrm{p} \leq 0 \cdot 05$, green asterisk representing a site with positive selection. Triangles show the sites identified in colistin resistant isolates in previous literatures.

This figure appears in colour in the online version of $J A C$ and in black and white in the print version of $J A C$. synonymous mutations in $p m r A$ and $p m r B$, which are responsible for resistance to colistin in $A$. baumannii are under neutral selection, most of which are non-polymorphic sites. Numbers in each set indicate the number of sites falling under the corresponding category. B) Volcano plot of the $d N-d S$ data for $p m r A B$ and gyrA plotted against $-\log _{10}$ of the $p$-value. The sites under adaptive selection in 505 PmrB and GyrA have been indicated.

506 This figure appears in colour in the online version of $J A C$ and in black and white in the print version 
Table 1. Molecular characters and other clinical details of isolates PKAB15 and PKAB19

Resistant Determinants

\begin{tabular}{|c|c|c|c|c|c|c|c|c|c|c|c|c|c|c|}
\hline & $b l a_{\mathrm{IMP}-1}$ & $b l a_{\text {OXA-23 }}$ & $b l a_{\text {OXA }-51}$ & $b l a_{\text {OXA }-58}$ & $b l a_{\mathrm{NDM}-1}$ & $b l a_{\text {PER-1 }}$ & $b l a_{\mathrm{ADC}}$ & $a d e B$ & $\operatorname{aac}(3)-I$ & $a a c(6)-I b$ & $\operatorname{aph}(3)-I$ & $\operatorname{ant}(3)-I$ & $r m t C$ & $\operatorname{arm} A$ \\
\hline PKAB15 & + & + & + & - & - & + & - & + & - & - & - & - & - & - \\
\hline PKAB19 & - & + & + & - & - & - & - & + & - & - & + & - & - & _512 \\
\hline
\end{tabular}

Biofilm production and Antimicrobial susceptibility ${ }^{a}$

513

\begin{tabular}{|c|c|c|c|c|c|c|c|c|c|c|}
\hline & $\begin{array}{l}\text { MEM } \\
\text { (mg/L) }\end{array}$ & $\begin{array}{l}\text { CAZ } \\
(\mathrm{mg} / \mathrm{L})\end{array}$ & $\begin{array}{l}\mathrm{CRO} \\
(\mathrm{mg} / \mathrm{L})\end{array}$ & $\begin{array}{l}\text { AMK } \\
(\mathrm{mg} / \mathrm{L})\end{array}$ & $\begin{array}{l}\text { GEN } \\
(\mathrm{mg} / \mathrm{L})\end{array}$ & $\begin{array}{l}\text { TOB } \\
(\mathrm{mg} / \mathrm{L})\end{array}$ & $\begin{array}{l}\text { TGC } \\
(\mathrm{mg} / \mathrm{L})\end{array}$ & $\begin{array}{l}\mathrm{CST} \\
(\mathrm{mg} / \mathrm{L})\end{array}$ & Biofilm $^{b}$ & 514 \\
\hline PKAB15 & $>256(\mathrm{R})$ & $>256(\mathrm{R})$ & $>256(\mathrm{R})$ & $>256(\mathrm{R})$ & $>256(\mathrm{R})$ & $>256(\mathrm{R})$ & $0.75(\mathrm{~S})$ & $3(\mathrm{R})$ & + & 515 \\
\hline PKAB19 & $32(\mathrm{R})$ & $32(\mathrm{R})$ & $>256(\mathrm{R})$ & $8(S)$ & $256(\mathrm{R})$ & $<2(\mathrm{~S})$ & $0.38(\mathrm{~S})$ & $3(\mathrm{R})$ & ++ & \\
\hline
\end{tabular}

${ }^{a} \mathrm{R}$ - Resistant, I - Intermediate, $\mathrm{S}$ - Sensitive, according to EUCAST Guidelines(EUCAST, 2017)

$\boldsymbol{b}_{+}-$Weakly positive $\left(\mathrm{OD}_{\text {Control }}<\mathrm{OD}<2 \mathrm{xOD}_{\text {Control }}\right),++-$ Strongly positive $(\mathrm{OD}>3 \mathrm{xOD}$ Control $)$

MEM - Meropenem, CAZ - Ceftazidime, CRO - Ceftriaxone, AMK - Amikacin, GEN - Gentamicin, TOB - Tobramycin, TGC - Tigecyclin, CST - Colistin

\section{Nucleotide sequence accession numbers}

Nucleotide sequences of pmrAB from Acinetobacter baumannii strains PKAB19 and PKAB15 have been deposited in GenBank under accession numbers MH925082 and MH925083, respectively. 
526 Table 2. Codon-wise mutation and selection analysis and the corresponding $p$-values for

$527 p m r A$. Only values for codons with non-zero normalized $d N-d S$ values are shown. Sites

528 reported to be associated with colistin resistant strains are shown in bold. $p$-values $>0.05$ are

529 shaded red, $<0.05$ shaded green, intermediate color is yellow. Normalized $d N-d \mathrm{~S}$ values $>0$

530 are shaded red, $<0$ shaded green, intermediate color is yellow.

\begin{tabular}{|c|c|c|c|}
\hline Codon & $p$-value & Normalized $d N-d S$ & $\begin{array}{l}\text { \#Non-synonymous } \\
\text { mutations }\end{array}$ \\
\hline 3 & 0.264358 & 1.58451 & 2 \\
\hline 4 & 0.296151 & -3.71198 & 0 \\
\hline 5 & 0.539133 & -2.125 & 0 \\
\hline 6 & 0.00820638 & 2.208 & 4 \\
\hline 8 & 0.450377 & 3.08981 & 2 \\
\hline 9 & 0.264775 & -4.15186 & 0 \\
\hline 10 & 0.459423 & 2.99064 & 6 \\
\hline 12 & 0.00515319 & 3.30361 & 7 \\
\hline 14 & 0.259259 & -4.94689 & 1 \\
\hline 15 & 0.453651 & -2.84841 & 3 \\
\hline 16 & 0.588192 & 3.67763 & 18 \\
\hline 17 & 0.037037 & -9.89377 & 0 \\
\hline 18 & 0.0366219 & -20.2495 & 88 \\
\hline 19 & 0.037037 & -9.89377 & 0 \\
\hline 20 & 0.538401 & 2.4815 & 3 \\
\hline 21 & 0.126661 & -7.37897 & 0 \\
\hline 25 & 0.337556 & -4.42948 & 0 \\
\hline 27 & 0.261537 & -4.38016 & 0 \\
\hline 29 & 0.0676334 & -8.80995 & 0 \\
\hline 31 & 0.555372 & -1.65067 & 1 \\
\hline 33 & 0.264775 & -4.15186 & 0 \\
\hline 34 & 0.333333 & -3.29792 & 0 \\
\hline 35 & 0.55381 & -2.12147 & 0 \\
\hline 36 & 0.459444 & -2.65666 & 2 \\
\hline 37 & 0.333333 & -3.29792 & 0 \\
\hline 38 & 0.174609 & -6.07459 & 0 \\
\hline 39 & 0.0123457 & -13.1917 & 0 \\
\hline 40 & 0.0394633 & -13.1752 & 0 \\
\hline 41 & 0.291797 & -4.25337 & 0 \\
\hline 42 & 0.111111 & -8.24481 & 1 \\
\hline 43 & 0.266116 & -4.38016 & 0 \\
\hline 44 & 0.51388 & 3.15339 & 101 \\
\hline 45 & 0.0694484 & -8.84626 & 0 \\
\hline 46 & 0.264775 & -4.15186 & 0 \\
\hline 48 & 0.188558 & -6.38329 & 0 \\
\hline 51 & 0.0342525 & -14.541 & 2 \\
\hline 52 & 0.0185623 & -12.4556 & 0 \\
\hline 53 & 0.168915 & -6.35978 & 0 \\
\hline 54 & 0.00115942 & -24.6886 & 1 \\
\hline 55 & 0.314606 & -4.02386 & 0 \\
\hline 56 & 0.0123457 & -13.1917 & 0 \\
\hline 59 & 0.264775 & -4.15186 & 0 \\
\hline 60 & 0.0123457 & -13.1917 & 0 \\
\hline
\end{tabular}


bioRxiv preprint doi: https://doi.org/10.1101/753665; this version posted September 15, 2019. The copyright holder for this preprint (which was not certified by peer review) is the author/funder, who has granted bioRxiv a license to display the preprint in perpetuity. It is made available under aCC-BY-NC-ND 4.0 International license.

\begin{tabular}{|c|c|c|c|}
\hline Codon & $p$-value & Normalized $d N-d S$ & $\begin{array}{l}\text { \#Non-synonymous } \\
\text { mutations }\end{array}$ \\
\hline 62 & 0.119672 & -10.7783 & 1 \\
\hline 63 & 0.333333 & -3.29792 & 0 \\
\hline 64 & 0.0150859 & -14.9871 & 0 \\
\hline 66 & 0.0397356 & -13.145 & 0 \\
\hline 67 & 0.00264645 & -18.0118 & 0 \\
\hline 68 & 0.111111 & -6.59585 & 0 \\
\hline 70 & 0.498667 & 3.29154 & 8 \\
\hline 71 & 0.333333 & -3.29792 & 0 \\
\hline 72 & 0.333333 & -3.29792 & 0 \\
\hline 73 & 0.037037 & -9.89377 & 0 \\
\hline 74 & 0.00411523 & -16.4896 & 0 \\
\hline 75 & 0.0123457 & -13.1917 & 0 \\
\hline 76 & 0.303064 & -4.28582 & 0 \\
\hline 77 & 0.305164 & -3.60236 & 0 \\
\hline 78 & 0.305164 & -3.60236 & 0 \\
\hline 79 & 0.338828 & -3.29792 & 0 \\
\hline 80 & 0.0009653 & -24.7344 & 5 \\
\hline 81 & 0.481296 & -2.97962 & 0 \\
\hline 82 & 0.708465 & 0.342856 & 10 \\
\hline 83 & 0.33968 & -4.4018 & 0 \\
\hline 84 & 0.172438 & -6.30536 & 0 \\
\hline 85 & 0.337556 & -4.42948 & 0 \\
\hline 86 & 0.173193 & -6.80852 & 3 \\
\hline 88 & 0.037037 & -9.89377 & 0 \\
\hline 90 & 0.0123457 & -13.1917 & 0 \\
\hline 91 & 0.166357 & -6.41356 & 0 \\
\hline 92 & 0.0701058 & -8.30372 & 0 \\
\hline 93 & 0.796512 & 3.35393 & 26 \\
\hline 94 & 0.112114 & -6.59585 & 0 \\
\hline 97 & 0.264775 & -4.15186 & 0 \\
\hline 98 & 0.284264 & -4.15186 & 0 \\
\hline 99 & 0.546441 & -2.13659 & 0 \\
\hline 100 & 0.305164 & -3.60236 & 0 \\
\hline 101 & 0.263682 & -4.42059 & 0 \\
\hline 102 & 0.0123457 & -13.1917 & $\mathbf{0}$ \\
\hline 103 & 0.284264 & -4.15186 & 0 \\
\hline 104 & 0.00478642 & -17.4213 & 0 \\
\hline 105 & 0.265431 & 1.49679 & 1 \\
\hline 107 & 0.00474956 & -17.455 & 0 \\
\hline 108 & 0.161317 & -6.4 & 0 \\
\hline 109 & 0.037037 & -9.89377 & 0 \\
\hline 110 & 0.0178326 & -14.8407 & 1 \\
\hline 111 & 0.406641 & -3.30926 & 3 \\
\hline 112 & 0.291608 & -3.76981 & 0 \\
\hline 113 & 0.0701058 & -8.30372 & 0 \\
\hline 114 & $5.65 \mathrm{E}-06$ & -36.2772 & 0 \\
\hline 115 & 0.568532 & -2.02235 & 0 \\
\hline 116 & 0.109719 & -7.8853 & 0 \\
\hline 117 & 0.333333 & -3.29792 & 0 \\
\hline 118 & 0.333198 & 1.64879 & 1 \\
\hline 119 & 0.609372 & 4.51149 & 199 \\
\hline 120 & 0.00463535 & -16.4896 & 0 \\
\hline 122 & 0.260794 & -4.39264 & 0 \\
\hline 123 & 0.333333 & -3.29792 & 0 \\
\hline 124 & 0.33968 & -4.4018 & 0 \\
\hline
\end{tabular}


bioRxiv preprint doi: https://doi.org/10.1101/753665; this version posted September 15, 2019. The copyright holder for this preprint (which was not certified by peer review) is the author/funder, who has granted bioRxiv a license to display the preprint in perpetuity. It is made available under aCC-BY-NC-ND 4.0 International license.

\begin{tabular}{|c|c|c|c|}
\hline Codon & $p$-value & Normalized $d N-d S$ & $\begin{array}{l}\text { \#Non-synonymous } \\
\text { mutations }\end{array}$ \\
\hline 125 & 0.552136 & 3.28531 & 3 \\
\hline 126 & 0.0123457 & -13.1917 & 0 \\
\hline 127 & 0.119708 & -9.46518 & 27 \\
\hline 128 & 0.306009 & 1.90736 & 25 \\
\hline 129 & 0.458626 & 3.0322 & 26 \\
\hline 130 & 0.114213 & -8.84854 & 0 \\
\hline 131 & 0.352489 & -3.71363 & 0 \\
\hline 132 & 0.17445 & -6.26275 & 0 \\
\hline 133 & 0.811993 & 2.6014 & 63 \\
\hline 134 & 0.173347 & -6.80603 & 1 \\
\hline 135 & 0.00411523 & -16.4896 & 0 \\
\hline 136 & 0.265113 & 1.49589 & 1 \\
\hline 137 & 0.597828 & -1.8392 & 0 \\
\hline 139 & 0.550199 & -2.14243 & 0 \\
\hline 141 & 0.333195 & 1.64862 & 1 \\
\hline 142 & 0.258655 & -4.42898 & 0 \\
\hline 143 & 0.116565 & -8.75883 & 0 \\
\hline 144 & 0.00130132 & -20.7593 & 0 \\
\hline 146 & 0.00411523 & -16.4896 & 0 \\
\hline 147 & 0.000152416 & -26.3834 & 0 \\
\hline 148 & 0.0701058 & -8.30372 & 0 \\
\hline 149 & 0.263321 & -4.42665 & 0 \\
\hline 150 & 0.00147606 & -19.7875 & 0 \\
\hline 151 & 0.33968 & -4.4018 & 0 \\
\hline 152 & 0.333333 & -3.29792 & 0 \\
\hline 155 & 0.0296732 & -12.4095 & 0 \\
\hline 156 & 0.120704 & -6.59585 & 0 \\
\hline 158 & 0.333198 & 1.64879 & 1 \\
\hline 159 & 0.00448563 & -17.7063 & 0 \\
\hline 161 & 0.111111 & -6.59585 & 0 \\
\hline 162 & 0.305164 & -3.60236 & 0 \\
\hline 163 & 0.159045 & -6.34428 & 0 \\
\hline 165 & 0.260128 & -4.93241 & 1 \\
\hline 166 & 0.649555 & -0.85846 & 0 \\
\hline 168 & 0.0841187 & -9.40117 & 103 \\
\hline 169 & 0.0185623 & -12.4556 & 0 \\
\hline 173 & 0.517064 & -2.02165 & 5 \\
\hline 174 & 0.264775 & -4.15186 & 0 \\
\hline 175 & 0.33606 & -3.29792 & 0 \\
\hline 177 & 0.037037 & -9.89377 & 0 \\
\hline 178 & 0.0701058 & -8.30372 & 0 \\
\hline 179 & 0.45178 & -2.74555 & 0 \\
\hline 180 & 0.258614 & 1.54525 & 3 \\
\hline 185 & 0.264775 & -4.15186 & 0 \\
\hline 186 & 0.0701058 & -8.30372 & 0 \\
\hline 190 & 0.111111 & -6.59585 & 0 \\
\hline 191 & 0.037037 & -9.89377 & 0 \\
\hline 192 & 0.264775 & -4.15186 & 0 \\
\hline 193 & 0.0701058 & -8.30372 & 0 \\
\hline 194 & 0.00137174 & -19.7875 & 0 \\
\hline 196 & 0.259123 & -4.42098 & 0 \\
\hline 199 & 0.000152416 & -26.3834 & 0 \\
\hline 200 & 0.0701058 & -8.30372 & 0 \\
\hline 201 & 0.264775 & -4.15186 & 0 \\
\hline 202 & 0.0984731 & -8.25712 & 0 \\
\hline
\end{tabular}


bioRxiv preprint doi: https://doi.org/10.1101/753665; this version posted September 15, 2019. The copyright holder for this preprint (which was not certified by peer review) is the author/funder, who has granted bioRxiv a license to display the preprint in perpetuity. It is made available under aCC-BY-NC-ND 4.0 International license.

531

\begin{tabular}{|l|l|l|l|}
\hline Codon & $p$-value & Normalized $d N-d S$ & $\begin{array}{l}\text { \#Non-synonymous } \\
\text { mutations }\end{array}$ \\
\hline 203 & 0.091224 & -7.77091 & 0 \\
\hline 204 & 0.037037 & -9.89377 & 0 \\
\hline 205 & 0.266116 & -4.38016 & 0 \\
\hline $\mathbf{2 0 6}$ & $\mathbf{0 . 0 3 3 0 2 1 6}$ & $-\mathbf{1 3 . 4 3 3 3}$ & $\mathbf{1}$ \\
\hline 207 & 0.333333 & -3.29792 & 0 \\
\hline 209 & 0.0701058 & -8.30372 & 0 \\
\hline 211 & $1.39 \mathrm{E}-11$ & -75.919 & 0 \\
\hline 212 & 0.505965 & -2.94466 & 0 \\
\hline 213 & 0.00411523 & -16.4896 & 0 \\
\hline 214 & 0.305164 & -3.60236 & 0 \\
\hline 215 & 0.505964 & -2.94466 & 0 \\
\hline 217 & 0.333102 & -3.86639 & 0 \\
\hline 218 & 0.111111 & -6.59585 & 0 \\
\hline 219 & 0.0808058 & -8.30372 & 0 \\
\hline 220 & 0.333165 & 1.64855 & 1 \\
\hline 221 & 0.295666 & -4.26472 & 0 \\
\hline 222 & 0.555472 & -1.65007 & 2 \\
\hline 223 & 0.337557 & -4.42948 & 0 \\
\hline 224 & 0.354016 & -3.29792 & 0 \\
\hline & & & \\
\hline
\end{tabular}


533 Table 3. Codon-wise mutation and selection analysis and the corresponding $p$-values for

$534 \quad p m r B$. Only values for codons with non-zero normalized $d N-d S$ values are shown. Sites

535 reported to be associated with colistin resistant strains are shown in bold. $p$-values $>0.05$ are

536 shaded red, $<0.05$ shaded green, intermediate color is yellow. Normalized $d N-d \mathrm{~S}$ values $>0$

537 are shaded red, $<0$ shaded green, intermediate color is yellow.

\begin{tabular}{|c|c|c|c|}
\hline Codon & $p$-value & $\begin{array}{l}\text { Normalized } \\
d N-d S\end{array}$ & $\begin{array}{l}\text { \#Non-synonymous } \\
\text { mutations }\end{array}$ \\
\hline 5 & 0.75505 & 0.02736 & 5 \\
\hline 6 & 0.23262 & 0.86962 & 1 \\
\hline 8 & 0.00182 & -14.404 & 0 \\
\hline 9 & 0.58075 & -1.0608 & 0 \\
\hline 13 & 0.55552 & 1.84816 & 4 \\
\hline 14 & 0.74388 & 3.18365 & 6 \\
\hline 16 & 0.24758 & 0.81882 & 2 \\
\hline 17 & 0.67942 & -0.0326 & 5 \\
\hline 19 & 0.08941 & -4.1207 & 0 \\
\hline 21 & 0.33333 & 0.92411 & 8 \\
\hline 23 & 0.27049 & -2.2776 & 0 \\
\hline 25 & 0.75816 & 3.51406 & 57 \\
\hline 27 & 0.25223 & 0.82388 & 3 \\
\hline 29 & 0.07326 & -4.9802 & 0 \\
\hline 30 & 0.05913 & -5.4891 & 0 \\
\hline 31 & 0.80176 & 3.69314 & 8 \\
\hline 33 & 0.58791 & -0.7609 & 2 \\
\hline 34 & 0.28581 & -2.8642 & 0 \\
\hline 36 & 0.33333 & -1.8482 & 0 \\
\hline 37 & 0.24741 & -2.4901 & 0 \\
\hline 40 & 0.3244 & -2.1937 & 0 \\
\hline 42 & 0.33333 & -1.8482 & 0 \\
\hline 43 & 0.28627 & 1.14615 & 4 \\
\hline 45 & 0.59629 & 0.97052 & 15 \\
\hline 46 & 0.27067 & -2.4901 & 0 \\
\hline 47 & 0.5053 & -1.331 & 0 \\
\hline 48 & 0.33333 & -1.8482 & 0 \\
\hline 49 & 0.22739 & -2.8632 & 0 \\
\hline 50 & 0.02931 & -6.6678 & 0 \\
\hline 51 & 0.33333 & -1.8482 & 0 \\
\hline 53 & 0.23685 & -2.7488 & 0 \\
\hline 54 & 0.15783 & -4.1439 & 35 \\
\hline 55 & 0.25926 & -2.7723 & 2 \\
\hline 56 & 0.5046 & -1.3278 & 0 \\
\hline 58 & 0.03704 & -5.5447 & 0 \\
\hline 60 & 0.236 & -4.0995 & 2 \\
\hline 61 & 0.57394 & 2.45633 & 4 \\
\hline 62 & 0.56844 & 2.64003 & 7 \\
\hline 63 & $7.39 \mathrm{E}-13$ & -49.802 & 0 \\
\hline 64 & 0.67964 & 3.27573 & 20 \\
\hline 65 & 0.44231 & -1.6114 & 28 \\
\hline 67 & 0.41978 & -0.0866 & 28 \\
\hline 69 & 0.27067 & -2.4901 & 0 \\
\hline
\end{tabular}


bioRxiv preprint doi: https://doi.org/10.1101/753665; this version posted September 15, 2019. The copyright holder for this preprint (which was not certified by peer review) is the author/funder, who has granted bioRxiv a license to display the preprint in perpetuity. It is made available under aCC-BY-NC-ND 4.0 International license.

\begin{tabular}{|c|c|c|c|}
\hline Codon & $p$-value & $\begin{array}{l}\text { Normalized } \\
d N-d S\end{array}$ & $\begin{array}{l}\text { \#Non-synonymous } \\
\text { mutations }\end{array}$ \\
\hline 70 & 0.24741 & -2.4901 & 0 \\
\hline 74 & 0.19416 & -3.1985 & 0 \\
\hline 76 & 0.1748 & -4.2132 & 35 \\
\hline 78 & $1.37 \mathrm{E}-08$ & -30.905 & 0 \\
\hline 79 & 0.0036 & 2.24631 & 2 \\
\hline 80 & 0.33333 & -1.8482 & $\mathbf{0}$ \\
\hline 82 & 0.24247 & -2.7524 & 0 \\
\hline 83 & 0.06121 & -4.9802 & 0 \\
\hline 84 & 0.29742 & -2.7524 & 0 \\
\hline 85 & 0.03704 & -5.5447 & 0 \\
\hline 86 & 0.24741 & 0.81861 & 28 \\
\hline 87 & 0.50023 & -1.3073 & 0 \\
\hline 88 & 0.26749 & -2.7265 & 2 \\
\hline 89 & 0.43388 & -1.6695 & 3 \\
\hline 91 & 0.45724 & -1.5569 & 0 \\
\hline 92 & 0.24741 & -2.4901 & 0 \\
\hline 93 & 0.74348 & -0.0338 & 28 \\
\hline 94 & 0.07402 & -6.2937 & 2 \\
\hline 96 & 0.11111 & -3.6965 & 0 \\
\hline 99 & 0.82493 & 1.76685 & 35 \\
\hline 101 & 0.33333 & -1.8482 & 0 \\
\hline 102 & 0.12153 & -3.6965 & 0 \\
\hline 103 & 0.06121 & -4.9802 & 0 \\
\hline 104 & 0.27067 & -2.4901 & 0 \\
\hline 105 & 0.00051 & -12.938 & 0 \\
\hline 106 & 0.24743 & 0.81867 & 1 \\
\hline 109 & 0.5373 & 1.81139 & 7 \\
\hline 110 & 0.72533 & 0.40327 & 35 \\
\hline 111 & 0.11122 & -3.6965 & 0 \\
\hline 112 & 0.3285 & 1.52432 & 35 \\
\hline 113 & 0.32791 & 0.91666 & 7 \\
\hline 114 & 0.08543 & -4.5292 & 0 \\
\hline 115 & 0.11109 & -4.621 & 2 \\
\hline 116 & 0.27065 & 0.92403 & 1 \\
\hline 118 & 0.25475 & -2.6568 & 0 \\
\hline 119 & 0.40741 & -1.8482 & 4 \\
\hline 120 & 0.25007 & -2.6131 & 0 \\
\hline 121 & 0.24438 & -2.7308 & $\mathbf{0}$ \\
\hline 122 & 0.24741 & -2.4901 & 0 \\
\hline 123 & 0.01983 & -7.4702 & 0 \\
\hline 124 & 0.34697 & -3.1326 & 2 \\
\hline 126 & 0.30008 & 1.16939 & 1 \\
\hline 127 & 0.5483 & -0.9621 & 7 \\
\hline 128 & $8.59 \mathrm{E}-07$ & -24.901 & 0 \\
\hline 129 & 0.29979 & -2.7306 & 0 \\
\hline 131 & 0.05609 & -5.4979 & 0 \\
\hline 132 & 0.04702 & -7.673 & 8 \\
\hline 133 & 0.55556 & -0.9241 & 4 \\
\hline 134 & 0.33321 & 0.92395 & 2 \\
\hline 135 & 0.22887 & -2.8447 & 0 \\
\hline 137 & 0.5741 & -0.8505 & 2 \\
\hline 138 & 0.97399 & 5.54467 & 375 \\
\hline 140 & 0.23685 & -2.7488 & 0 \\
\hline 141 & 0.33331 & 0.92408 & 2 \\
\hline 143 & 0.03704 & -5.5447 & 0 \\
\hline
\end{tabular}


bioRxiv preprint doi: https://doi.org/10.1101/753665; this version posted September 15, 2019. The copyright holder for this preprint (which was not certified by peer review) is the author/funder, who has granted bioRxiv a license to display the preprint in perpetuity. It is made available under aCC-BY-NC-ND 4.0 International license.

\begin{tabular}{|c|c|c|c|}
\hline Codon & $p$-value & $\begin{array}{l}\text { Normalized } \\
d N-d S\end{array}$ & $\begin{array}{l}\text { \#Non-synonymous } \\
\text { mutations }\end{array}$ \\
\hline 144 & 0.15348 & -4.159 & 1 \\
\hline 145 & 0.00882 & 2.47068 & 23 \\
\hline 146 & 0.06121 & -4.9802 & 0 \\
\hline 148 & 0.00015 & -14.786 & 0 \\
\hline 150 & 0.5046 & -1.3278 & 0 \\
\hline 152 & 0.29902 & -2.0603 & 0 \\
\hline 153 & 0.01367 & 9.48851 & 11 \\
\hline 154 & 0.25926 & -2.7723 & 3 \\
\hline 155 & 0.24759 & 0.8188 & 4 \\
\hline 156 & 0.03704 & -5.5447 & 0 \\
\hline 157 & 0.14703 & -4.19 & 0 \\
\hline 159 & 0.00013 & -17.562 & 1 \\
\hline 160 & 0.50737 & -1.3069 & 14 \\
\hline 161 & 0.25926 & -2.7723 & 1 \\
\hline 162 & 0.55556 & -0.9241 & 5 \\
\hline 163 & 0.75834 & 3.51471 & 7 \\
\hline 164 & 0.65538 & 2.63617 & 9 \\
\hline 165 & 0.5529 & -0.9379 & 27 \\
\hline 166 & 0.27169 & -2.6968 & 3 \\
\hline 167 & 0.11111 & -3.6965 & 0 \\
\hline 168 & 0.51381 & -1.2995 & 0 \\
\hline 169 & 0.2346 & -2.8447 & 0 \\
\hline 170 & 0.91393 & 2.80089 & 39 \\
\hline 171 & 0.01864 & -9.0238 & 0 \\
\hline 172 & 0.24741 & -2.4901 & 0 \\
\hline 173 & 0.57387 & -0.852 & 8 \\
\hline 176 & 0.00375 & -9.9603 & 0 \\
\hline 177 & 0.05605 & -5.5 & 0 \\
\hline 178 & 0.13718 & -3.8698 & 0 \\
\hline 179 & 0.35446 & -2.7808 & 34 \\
\hline 180 & 0.54467 & -1.1199 & 7 \\
\hline 181 & 0.21056 & -3.6934 & 5 \\
\hline 182 & 0.06121 & -4.9802 & 0 \\
\hline 183 & 0.11419 & -3.6965 & $\mathbf{0}$ \\
\hline 184 & 0.22729 & -2.8644 & $\mathbf{0}$ \\
\hline 185 & 0.13346 & -4.8381 & 1 \\
\hline 186 & 0.14473 & -4.0495 & 0 \\
\hline 187 & $2.85 \mathrm{E}-06$ & -28.648 & 4 \\
\hline 188 & 0.11111 & -3.6965 & 0 \\
\hline 190 & 0.22729 & -2.8644 & $\mathbf{0}$ \\
\hline 191 & 0.03704 & -5.5447 & 0 \\
\hline 192 & 0.78192 & 1.79977 & 7 \\
\hline 194 & 0.27072 & 0.92411 & 1 \\
\hline 197 & 0.23685 & -2.7488 & 0 \\
\hline 198 & 0.13218 & -3.4066 & 0 \\
\hline 199 & 0.2602 & -2.6265 & 0 \\
\hline 200 & 0.33333 & -1.8482 & 0 \\
\hline 201 & 0.11111 & -3.6965 & 0 \\
\hline 203 & 0.06121 & -4.9802 & 0 \\
\hline 206 & 0.00093 & -12.45 & 0 \\
\hline 207 & 0.5736 & -0.853 & 1 \\
\hline 208 & 0.67468 & 0.21796 & 21 \\
\hline 209 & 0.24741 & -2.4901 & 0 \\
\hline 210 & 0.23891 & 0.8543 & 27 \\
\hline 211 & $1.29 \mathrm{E}-06$ & -23.529 & 0 \\
\hline
\end{tabular}


bioRxiv preprint doi: https://doi.org/10.1101/753665; this version posted September 15, 2019. The copyright holder for this preprint (which was not certified by peer review) is the author/funder, who has granted bioRxiv a license to display the preprint in perpetuity. It is made available under aCC-BY-NC-ND 4.0 International license.

\begin{tabular}{|c|c|c|c|}
\hline Codon & $p$-value & $\begin{array}{l}\text { Normalized } \\
d N-d S\end{array}$ & $\begin{array}{l}\text { \#Non-synonymous } \\
\text { mutations }\end{array}$ \\
\hline 212 & 0.02674 & -6.181 & 0 \\
\hline 214 & 0.23391 & -2.8531 & 0 \\
\hline 215 & $6.27 \mathrm{E}-07$ & -24.027 & 0 \\
\hline 217 & 0.24741 & -2.4901 & 0 \\
\hline 218 & 0.40536 & -2.0004 & 1 \\
\hline 220 & 0.24279 & -2.7488 & 0 \\
\hline 221 & 0.28777 & -2.8447 & 0 \\
\hline 222 & 0.15337 & -4.1615 & 1 \\
\hline 223 & 0.29864 & -2.0629 & 0 \\
\hline 224 & 0.11111 & -3.6965 & 0 \\
\hline 226 & 0.86831 & 1.84822 & 21 \\
\hline 229 & 0.53891 & -1.1768 & 2 \\
\hline 230 & 0.00046 & -14.352 & 0 \\
\hline 231 & 0.483 & -1.7181 & 1 \\
\hline 232 & 0.42867 & -1.8548 & 19 \\
\hline 233 & 0.80247 & 3.69645 & 15 \\
\hline 234 & 0.11111 & -3.6965 & $\mathbf{0}$ \\
\hline 235 & 0.80225 & 0.92229 & 6 \\
\hline 236 & 0.25926 & -2.7723 & 3 \\
\hline 237 & 0.03526 & -6.2927 & 0 \\
\hline 238 & 0.00023 & -14.941 & 0 \\
\hline 239 & 0.75517 & 2.72389 & 4 \\
\hline 240 & 0.2854 & 1.14537 & 3 \\
\hline 241 & 0.11111 & -3.6965 & 0 \\
\hline 242 & 0.05965 & -5.465 & 0 \\
\hline 243 & 0.29898 & 0.87883 & 2 \\
\hline 244 & 0.25012 & -2.6126 & 0 \\
\hline 245 & 0.55144 & -0.985 & 7 \\
\hline 246 & 0.00023 & -14.941 & 0 \\
\hline 247 & 0.03024 & -9.7957 & 1 \\
\hline 248 & 0.05025 & -6.6009 & 2 \\
\hline 249 & 0.00137 & -11.089 & 0 \\
\hline 250 & 0.05688 & -5.4596 & 0 \\
\hline 251 & 0.44218 & 1.7085 & 5 \\
\hline 252 & 0.22712 & -2.8665 & 0 \\
\hline 253 & 0.59374 & -0.7965 & 4 \\
\hline 254 & 0.03541 & -6.2853 & 0 \\
\hline 256 & 0.24741 & -2.4901 & $\mathbf{0}$ \\
\hline 257 & 0.50503 & -1.3142 & 4 \\
\hline 258 & 0.24741 & -2.4901 & 0 \\
\hline 259 & 0.2374 & -2.8111 & 0 \\
\hline 260 & 0.55929 & -0.9126 & 1 \\
\hline 261 & 0.50023 & -1.3073 & 0 \\
\hline 262 & 0.04518 & -6.4739 & 1 \\
\hline 263 & 0.86792 & 4.61876 & 7 \\
\hline 265 & 0.30006 & -2.7282 & 0 \\
\hline 266 & 0.15337 & -4.1615 & 1 \\
\hline 267 & 0.80615 & 1.23405 & 102 \\
\hline 269 & 0.03704 & -5.5447 & 0 \\
\hline 270 & 0.51364 & 2.34224 & 9 \\
\hline 271 & 0.55531 & 1.84772 & 6 \\
\hline 272 & 0.50568 & -1.3328 & 0 \\
\hline 273 & 0.5391 & -0.9241 & 6 \\
\hline 274 & 0.67737 & 0.17619 & 7 \\
\hline 275 & 0.00686 & -10.165 & 1 \\
\hline
\end{tabular}


bioRxiv preprint doi: https://doi.org/10.1101/753665; this version posted September 15, 2019. The copyright holder for this preprint (which was not certified by peer review) is the author/funder, who has granted bioRxiv a license to display the preprint in perpetuity. It is made available under aCC-BY-NC-ND 4.0 International license.

\begin{tabular}{|c|c|c|c|}
\hline Codon & $p$-value & $\begin{array}{l}\text { Normalized } \\
d N-d S\end{array}$ & $\begin{array}{l}\text { \#Non-synonymous } \\
\text { mutations }\end{array}$ \\
\hline 277 & 0.28777 & -2.8447 & 0 \\
\hline 279 & 0.11111 & -3.6965 & 0 \\
\hline 280 & 0.33333 & 0.92411 & 7 \\
\hline 282 & 0.06121 & -4.9802 & 0 \\
\hline 283 & 0.05268 & 0.65033 & 7 \\
\hline 284 & 0.69625 & -0.0465 & 8 \\
\hline 285 & 0.01324 & -8.2554 & 0 \\
\hline 286 & 0.03704 & -5.5447 & 0 \\
\hline 287 & 0.11111 & -3.6965 & 0 \\
\hline 288 & 0.0025 & -12.454 & 7 \\
\hline 289 & 0.6288 & 2.772 & 7 \\
\hline 290 & 0.24741 & -2.4901 & 0 \\
\hline 291 & 0.28816 & -2.8408 & 0 \\
\hline 292 & 0.11121 & -4.6185 & 1 \\
\hline 294 & 0.25765 & -3.3392 & 3 \\
\hline 295 & 0.33333 & -1.8482 & 0 \\
\hline 297 & 0.25475 & -2.6568 & 0 \\
\hline 298 & 0.24748 & 0.81869 & 1 \\
\hline 299 & 0.26088 & -2.4901 & 0 \\
\hline 300 & 0.11111 & -3.6965 & 0 \\
\hline 301 & 0.23981 & -3.7899 & 2 \\
\hline 302 & 0.29971 & -2.7314 & 0 \\
\hline 303 & 0.45781 & -1.5103 & 0 \\
\hline 304 & 0.00015 & -14.786 & 0 \\
\hline 305 & 0.24741 & -2.4901 & 0 \\
\hline 306 & 0.12624 & -3.9035 & 0 \\
\hline 307 & 0.33333 & -1.8482 & 0 \\
\hline 308 & 0.00193 & 1.2334 & 2 \\
\hline 311 & 0.22725 & -2.865 & 0 \\
\hline 312 & 0.29902 & -2.0603 & 0 \\
\hline 313 & 0.24741 & -2.4901 & 0 \\
\hline 314 & 0.5046 & -1.3278 & 0 \\
\hline 315 & 0.21062 & -3.6929 & 3 \\
\hline 318 & 0.32788 & -2.7169 & 1 \\
\hline 319 & 0.15334 & -4.162 & 2 \\
\hline 320 & 0.22712 & -3.9869 & 32 \\
\hline 321 & 0.00686 & -10.165 & 1 \\
\hline 322 & 0.03073 & -7.3382 & 28 \\
\hline 323 & 0.22731 & -2.8642 & 0 \\
\hline 325 & 0.24741 & -2.4901 & 0 \\
\hline 327 & 0.00048 & -15.303 & 7 \\
\hline 328 & 0.01195 & -8.5438 & 0 \\
\hline 329 & 0.33333 & -1.8482 & 0 \\
\hline 330 & 0.11111 & -3.6965 & 0 \\
\hline 331 & 0.33333 & -1.8482 & 0 \\
\hline 332 & 0.43366 & 1.63747 & 2 \\
\hline 333 & 0.58216 & -0.837 & 3 \\
\hline 334 & 0.29902 & -2.0603 & 0 \\
\hline 336 & 0.24752 & 0.81872 & 4 \\
\hline 337 & 0.57377 & -0.8527 & 3 \\
\hline 338 & 0.50539 & 1.36257 & 1 \\
\hline 341 & 0.06121 & -4.9802 & 0 \\
\hline 342 & 0.33333 & -1.8482 & 0 \\
\hline 343 & 0.08941 & -4.1207 & 0 \\
\hline 344 & 0.24232 & -2.7541 & 0 \\
\hline
\end{tabular}


bioRxiv preprint doi: https://doi.org/10.1101/753665; this version posted September 15, 2019. The copyright holder for this preprint (which was not certified by peer review) is the author/funder, who has granted bioRxiv a license to display the preprint in perpetuity. It is made available under aCC-BY-NC-ND 4.0 International license.

\begin{tabular}{|c|c|c|c|}
\hline Codon & $p$-value & $\begin{array}{l}\text { Normalized } \\
d N-d S\end{array}$ & $\begin{array}{l}\text { \#Non-synonymous } \\
\text { mutations }\end{array}$ \\
\hline 345 & 0.00537 & -9.9603 & 0 \\
\hline 346 & 0.01783 & -8.317 & 1 \\
\hline 347 & 0.00015 & -14.786 & 0 \\
\hline 349 & 0.19913 & -4.3902 & 7 \\
\hline 350 & 0.33333 & -1.8482 & 0 \\
\hline 351 & 0.0321 & -8.5923 & 7 \\
\hline 353 & 0.43361 & -1.6715 & 1 \\
\hline 354 & 0.29902 & -2.0603 & 0 \\
\hline 355 & 0.36127 & -1.8482 & 0 \\
\hline 357 & 0.46228 & -1.5844 & 7 \\
\hline 358 & 0.01235 & -7.3929 & 0 \\
\hline 359 & 0.45386 & -1.5269 & 7 \\
\hline 360 & 0.55404 & 1.85946 & 217 \\
\hline 362 & 0.77995 & 0.9784 & 36 \\
\hline 363 & 0.01701 & -10.645 & 35 \\
\hline 364 & 0.03704 & -5.5447 & 0 \\
\hline 365 & 0.26091 & 0.87901 & 1 \\
\hline 366 & 0.46786 & -1.4329 & 1 \\
\hline 368 & 0.29902 & -2.0603 & 0 \\
\hline 371 & 0.06121 & -4.9802 & 0 \\
\hline 372 & 0.2592 & -2.773 & 1 \\
\hline 373 & 0.33333 & -1.8482 & 0 \\
\hline 374 & 0.01481 & -7.3929 & 0 \\
\hline 375 & 0.00318 & -12.57 & 0 \\
\hline 376 & 0.00375 & -9.9603 & 0 \\
\hline 377 & 0.33333 & -1.8482 & 0 \\
\hline 379 & 0.24741 & 0.81861 & 7 \\
\hline 380 & 0.07326 & -4.9802 & 0 \\
\hline 381 & 0.24741 & -2.4901 & 0 \\
\hline 382 & 0.05423 & -5.7317 & 0 \\
\hline 383 & 0.00137 & -11.089 & 0 \\
\hline 384 & 0.1351 & -3.3685 & 0 \\
\hline 385 & 0.0145 & -8.2104 & 0 \\
\hline 386 & 0.33495 & -1.8393 & 0 \\
\hline 387 & 0.24743 & 0.81867 & 1 \\
\hline 389 & 0.01261 & -7.3777 & 0 \\
\hline 390 & 0.01235 & -7.3929 & 0 \\
\hline 391 & 0.00093 & -12.45 & 0 \\
\hline 392 & 0.01514 & -7.4702 & 0 \\
\hline 393 & 0.43363 & -1.6714 & 1 \\
\hline 395 & 0.01325 & -8.2534 & 0 \\
\hline 397 & 0.12189 & -3.6965 & 0 \\
\hline 398 & 0.00023 & -14.941 & 0 \\
\hline 399 & $1.88 \mathrm{E}-06$ & -22.179 & 0 \\
\hline 400 & 0.01645 & -7.8731 & 0 \\
\hline 402 & 0.51847 & -1.2809 & 0 \\
\hline 403 & 0.04535 & -7.3997 & 4 \\
\hline 405 & 0.33333 & -1.8482 & 0 \\
\hline 406 & 0.24741 & -2.4901 & 0 \\
\hline 407 & 0.35538 & -1.8041 & 0 \\
\hline 408 & 0.55546 & 1.8481 & 2 \\
\hline 411 & 0.47862 & -1.3634 & 0 \\
\hline 412 & 0.58857 & -0.7681 & 0 \\
\hline 414 & 0.33329 & 0.92405 & 1 \\
\hline 416 & 0.25964 & -2.6216 & 0 \\
\hline
\end{tabular}


bioRxiv preprint doi: https://doi.org/10.1101/753665; this version posted September 15, 2019. The copyright holder for this preprint (which was not certified by peer review) is the author/funder, who has granted bioRxiv a license to display the preprint in perpetuity. It is made available under aCC-BY-NC-ND 4.0 International license.

\begin{tabular}{|c|c|c|c|}
\hline Codon & $p$-value & $\begin{array}{l}\text { Normalized } \\
d N-d S\end{array}$ & $\begin{array}{l}\text { \#Non-synonymous } \\
\text { mutations }\end{array}$ \\
\hline 417 & 0.33333 & -1.8482 & 0 \\
\hline 418 & 0.60593 & -0.6736 & 1 \\
\hline 419 & 0.24741 & -2.4901 & 0 \\
\hline 420 & 0.16811 & -4.2674 & 7 \\
\hline 421 & 0.24741 & -2.4901 & 0 \\
\hline 422 & 0.50567 & -1.3328 & 0 \\
\hline 423 & $2.45 \mathrm{E}-06$ & -24.624 & 0 \\
\hline 424 & 0.33489 & -1.8397 & 0 \\
\hline 425 & 0.33333 & -1.8482 & 0 \\
\hline 426 & 0.33619 & -1.8482 & 0 \\
\hline 428 & 0.11301 & -3.6965 & 0 \\
\hline 429 & 0.03704 & -5.5447 & 0 \\
\hline 430 & 0.25462 & -2.6556 & 0 \\
\hline 431 & $5.08 \mathrm{E}-05$ & -16.634 & 0 \\
\hline 433 & 0.02621 & -8.4657 & 0 \\
\hline 434 & 0.33333 & -1.8482 & 0 \\
\hline 435 & 0.2346 & -2.8447 & 0 \\
\hline 436 & 0.25206 & -2.8409 & 7 \\
\hline 438 & 0.24743 & 0.81867 & 1 \\
\hline 439 & 0.7257 & 1.20481 & 7 \\
\hline 440 & 0.57416 & -0.8516 & 63 \\
\hline 442 & 0.11111 & -3.6965 & 0 \\
\hline 444 & 0.42936 & -3.1198 & 883 \\
\hline
\end{tabular}




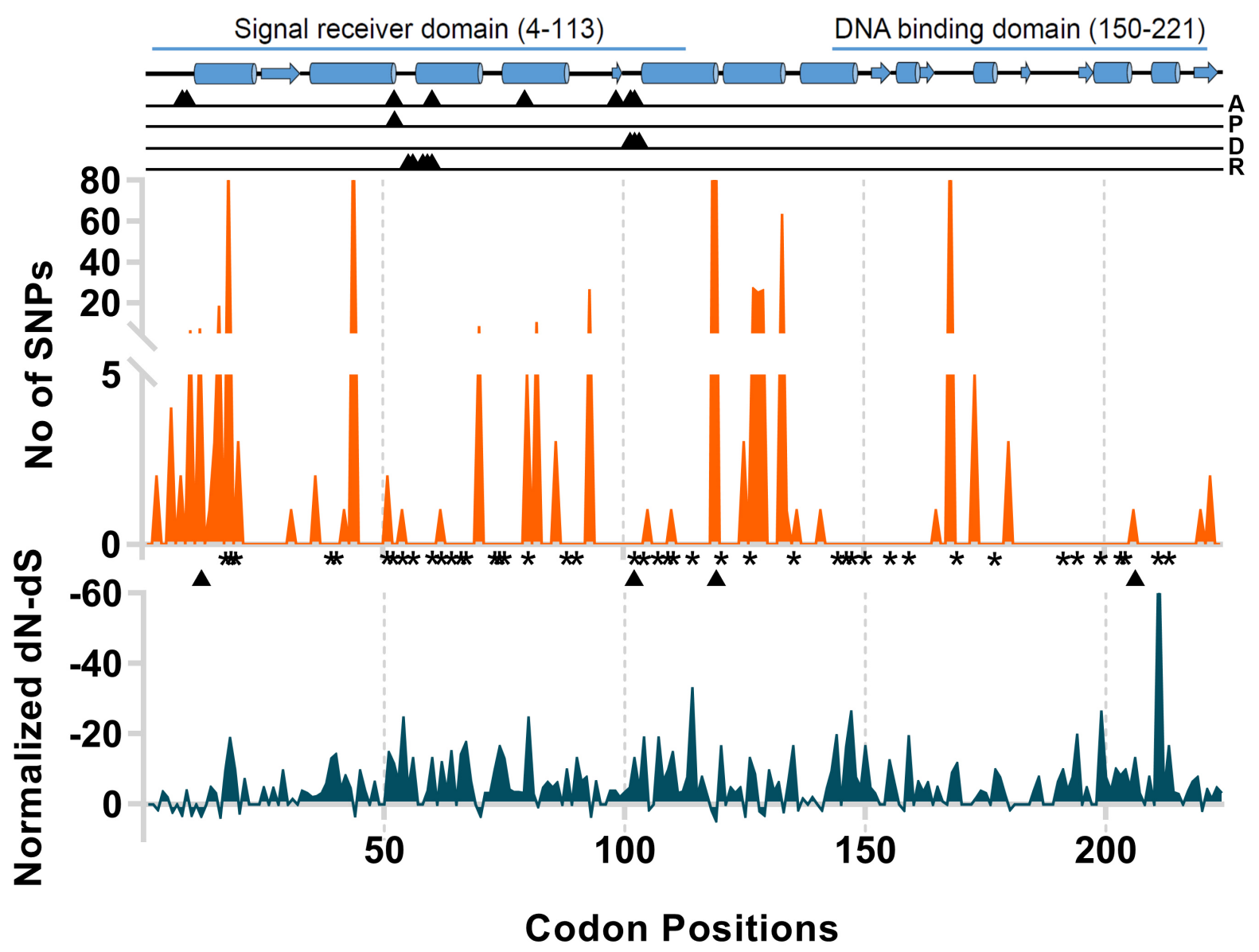




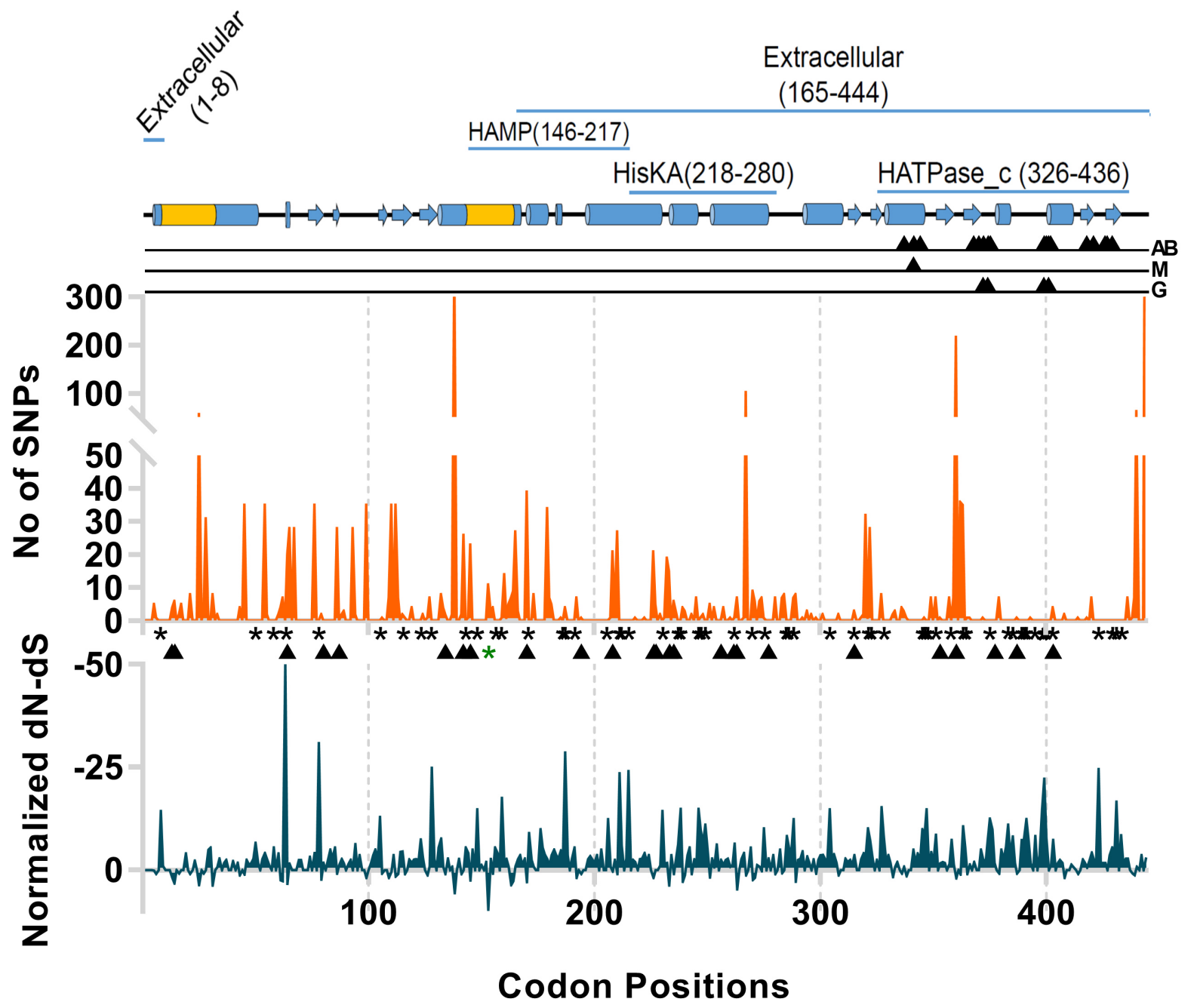




\section{Figure 3}
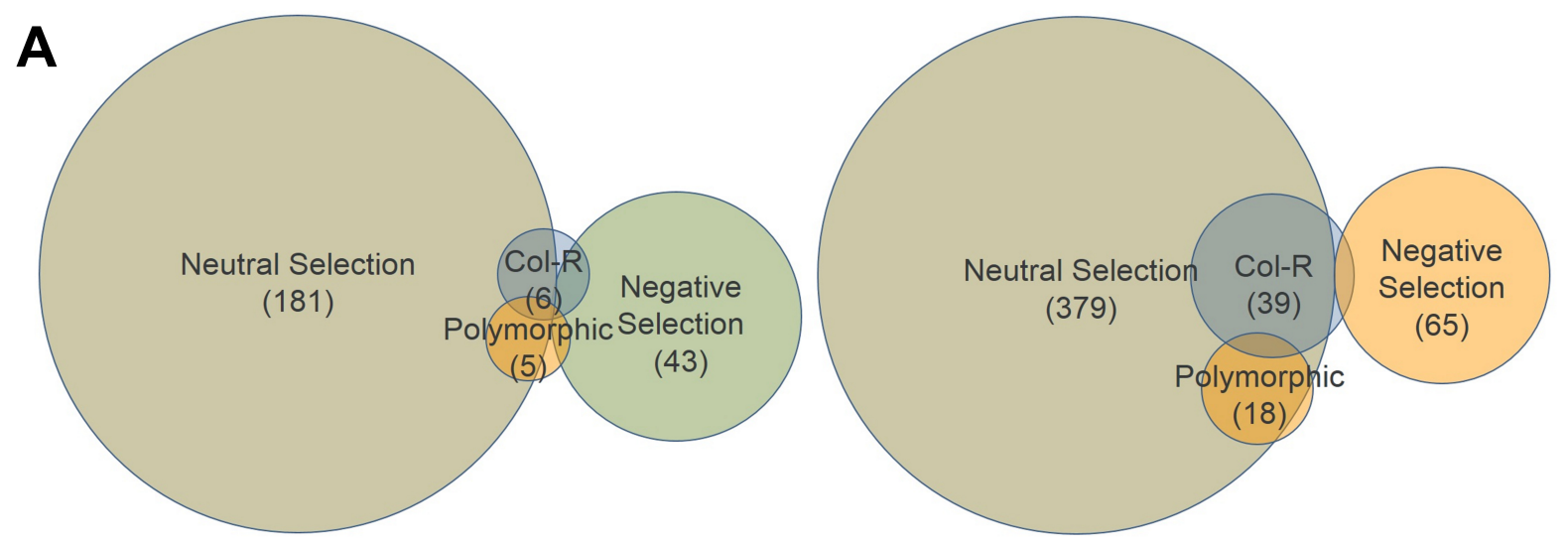

B

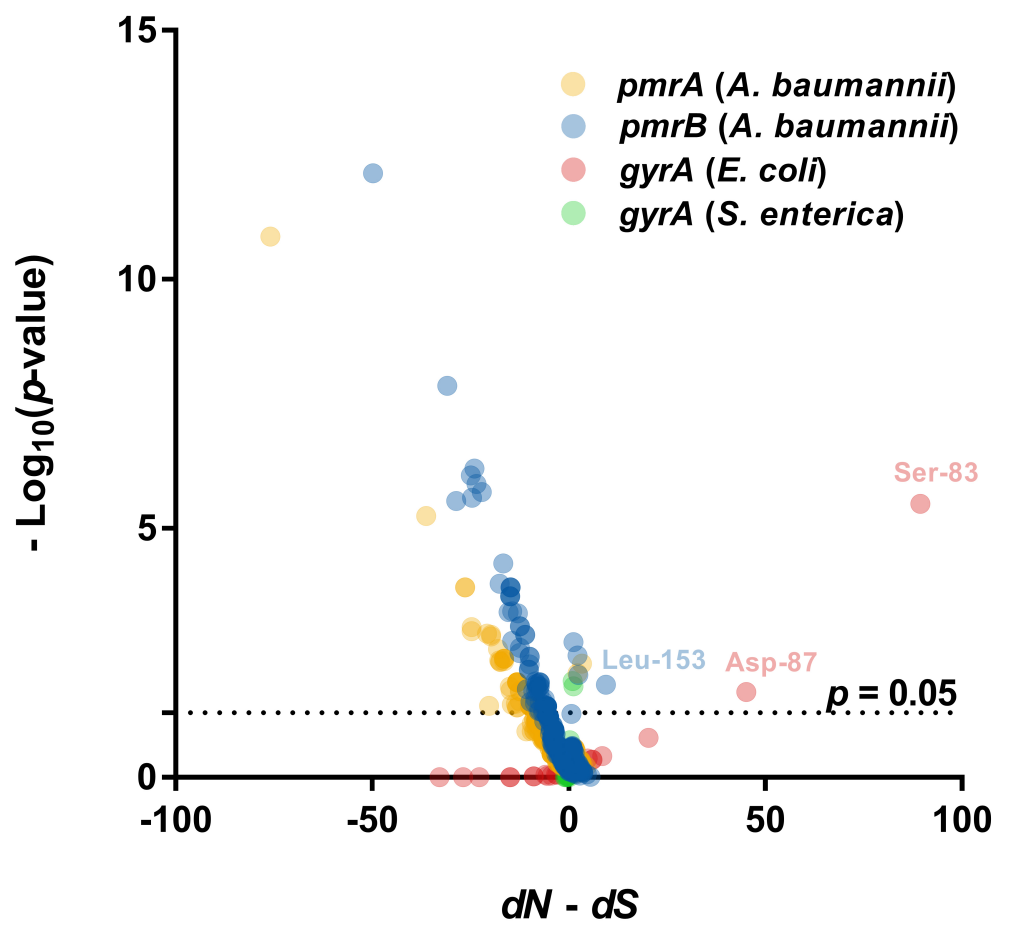

